\title{
Safety and efficacy of different anesthetic regimens for parturients with COVID-19 undergoing Cesarean delivery: a case series of 17 patients
}

\section{Sécurité et efficacité de différents modes d'anesthésie pour des parturientes infectées par la COVID-19 accouchant par césarienne : une série de 17 cas}

\author{
Rong Chen, MD • Yuan Zhang, MD • Lei Huang, MD, PhD • Bi-heng Cheng, MD, PhD • \\ Zhong-yuan Xia, MD, PhD • Qing-tao Meng, MD, PhD
}

Received: 1 March 2020/Revised: 10 March 2020/ Accepted: 10 March 2020/Published online: 16 March 2020

(C) Canadian Anesthesiologists' Society 2020

\begin{abstract}
Purpose To assess the management and safety of epidural or general anesthesia for Cesarean delivery in parturients with coronavirus disease (COVID-19) and their newborns, and to evaluate the standardized procedures for protecting medical staff.

Methods We retrospectively reviewed the cases of parturients diagnosed with severe acute respiratory syndrome coronavirus (SARS-CoV-2) infection disease (COVID-19). Their epidemiologic history, chest computed tomography scans, laboratory measurements, and SARS-
\end{abstract}

Rong Chen and Yuan Zhang have contributed equally to this work.

Zhong-yuan Xia and Qing-tao Meng share senior authorship.

R. Chen, MD · Y. Zhang, MD · Q. Meng, MD, PhD ( $ه)$ Department of Anesthesiology, Renmin Hospital of Wuhan University, Wuhan 430060, China

e-mail: mengqingtao2018@126.com

Department of Anesthesiology, East Hospital, Renmin Hospital of Wuhan University, Wuhan, China

L. Huang, MD, PhD

Department of Anesthesiology, East Hospital, Renmin Hospital of Wuhan University, Wuhan, China

B. Cheng, MD, PhD

Department of Obstetric, East Hospital, Renmin Hospital of Wuhan University, Wuhan, China

Z. Xia, MD, PhD

Department of Anesthesiology, Renmin Hospital of Wuhan University, Wuhan 430060, China
CoV-2 nucleic acid positivity were evaluated. We also recorded the patients' demographic and clinical characteristics, anesthesia and surgery-related data, maternal and neonatal complications, as well as the health status of the involved medical staff.

Results The clinical characteristics of 17 pregnant women infected with SARS-CoV-2 were similar to those previously reported in non-pregnant adult patients. All of the 17 patients underwent Cesarean delivery with anesthesia performed according to standardized anesthesia/surgery procedures. Fourteen of the patients underwent continuous epidural anesthesia with 12 experiencing significant intraoperative hypotension. Three patients received general anesthesia with tracheal intubation because emergency surgery was needed. Three of the parturients are still recovering from their Cesarean delivery and are receiving in-hospital treatment for COVID-19. Three neonates were born prematurely. There were no deaths or serious neonatal asphyxia events. All neonatal SARSCoV-2 nucleic acid tests were negative. No medical staff were infected throughout the patient care period.

Conclusions Both epidural and general anesthesia were safely used for Cesarean delivery in the parturients with COVID-19. Nevertheless, the incidence of hypotension during epidural anesthesia appeared excessive. Proper patient transfer, medical staff access procedures, and effective biosafety precautions are important to protect medical staff from COVID-19.

\section{Résumé}

Objectif Évaluer la gestion et la sécurité de l'anesthésie péridurale ou de l'anesthésie générale pour un 
accouchement par césarienne chez des parturientes infectées par la maladie à coronavirus 2019 (COVID-19) et pour leurs nouveau-nés, et évaluer les procédures standardisées visant la protection du personnel médical.

Méthodes Nous avons revu de manière rétrospective les cas de parturientes ayant un diagnostic de syndrome respiratoire aigu sévère lié à l'infection (SARS-CoV-2) par le coronavirus (COVID-19). L'enquête épidémiologique, leurs examens de tomodensitométrie thoracique, les analyses de laboratoire et leur positivité pour l'acide nucléique du SARS-CoV-2 ont été évalués. Nous avons également consigné les caractéristiques démographiques et cliniques des patientes, les données liées à l'anesthésie et à la chirurgie, les complications maternelles et néonatales, ainsi que l'état de santé du personnel médical concerné. Résultats Les caractéristiques cliniques des 17 femmes enceintes infectées par le SARS-CoV-2 étaient semblables à celles précédemment rapportées chez des patientes adultes non enceintes. Les 17 patientes ont subi un accouchement par césarienne sous anesthésie effectué selon les procédures standardisées d'anesthésie et de chirurgie. Parmi les quatorze patientes ayant eu une anesthésie péridurale continue, 12 patientes ont présenté une hypotension peropératoire significative. Trois patientes ont accouché sous anesthésie générale avec intubation trachéale, car nécessitant une chirurgie d'urgence. Trois parturientes sont encore en convalescence après leur accouchement par césarienne et reçoivent un traitement à l'hôpital pour la COVID-19. Trois nouveau-nés sont nés prématurément. Il n'y a pas eu de décès ou d'événement asphyxique néonatal grave. Toutes les recherches d'acide nucléique du SARS-CoV-2 chez les nouveau-nés ont été négatives. Aucun membre du personnel médical n'a été infecté pendant la durée des soins aux patientes.

Conclusions L'anesthésie par péridurale et l'anesthésie générale ont été utilisées sans danger pour l'accouchement par césarienne de parturientes atteintes de COVID-19. Cependant, l'incidence de l'hypotension au cours de l'anesthésie péridurale a paru excessive. Un transfert approprié des patientes, les procédures d'accès du personnel médical et des précautions efficaces de biosécurité sont importants pour protéger le personnel médical contre la COVID-19.

Since December 2019, a new severe acute respiratory syndrome coronavirus (SARS-CoV-2) infection disease (COVID-19) has been reported. The outbreak originated in Wuhan before spreading throughout China and the rest of the world. ${ }^{1,2}$ COVID-19 is a contagious pulmonary infectious disease with respiratory symptoms similar to those seen in the previously reported SARS epidemic in $2003{ }^{3}$ Respiratory droplets and close contact transmission are the main routes of transmission. There is also a possibility of aerosol transmission in a relatively closed environment when exposed to high concentrations of aerosol for a protracted period of time. ${ }^{4}$ Parturients have relatively depressed immunity and could theoretically be at higher risk from infection of this virus. Thus, SARS-CoV-2 virus infection during pregnancy is reported to be a serious threat to pregnant women and their fetuses. ${ }^{5}$ Nevertheless, the clinical manifestations of SARS-CoV-2-infected parturients and their babies remains unknown.

As of January 2020, the Renmin hospital of Wuhan University has been designated as the diagnostic and treatment centre for pregnant women infected with SARSCoV-2. Herein, we retrospectively review 17 cases of the SARS-CoV-2 infected pregnant women who underwent Cesarean delivery.

\section{Methods}

Patients and diagnosis

This study was approved by the Institutional Review Board at Renmin hospital of Wuhan University (No. WDRY2020-K077, 2 Feb 2020). Cases of pregnant women with COVID-19 who were admitted to Renmin hospital of Wuhan University from 30 January to 23 February 2020 were reviewed. After obtaining written informed consent, all clinical data were independently collected by two investigators. The diagnosis of COVID-19 followed the diagnostic criteria established by the New Coronavirus Pneumonia Prevention and Control Program (sixth edition) issued by the National Health Commission of China. Nasal swab samples from high-risk pregnant women and their newborns were tested for SARS-CoV-2 virus using a kit (BioGerm, Shanghai, China) according to the World Health Organization guidelines for reverse transcriptase polymerase chain reaction (RT-PCR) (also recommended by the Chinese Center for Disease Control and Prevention in Beijing, China). Chest computed tomography (CT) scans of all infected pregnant women were performed and reviewed as part of their pre-partum assessment. These scans were reviewed for the usual characteristic signs of COVID-19, including peripheral and/or sub-pleural ground-glass opacities.

Operating room preparation, personnel entry and exit procedures, and medical staff protection

Appropriate personnel protection equipment (PPE) was used in different zones of the operation room. Biosafety 
level-3 (BSL-3) protective medical equipment was worn during the operation, including N95 masks, goggles, protective suits, disposable medical caps, and medical rubber gloves. For care of the patients who received general anesthesia and endotracheal intubation, the anesthesiologist used a powered air-purifying respirator. ${ }^{4}$

Parturients were transferred between the isolation ward and the operating room by a negative pressure isolation transfer cabin that can carry one patient over a short distance in a stretcher and stretcher vehicle, and were transported by staff wearing BSL-3 protective medical equipment. The parturients also wore regular surgical masks throughout the process to reduce viral spread.

Negative pressure operating rooms were used for Cesarean delivery of parturients with COVID-19. Medical personnel entered and exited the operating room in strict accordance with the principles of clean area, contaminated pollution area, and two buffer zones (Fig. 1). Designated nurses ensured the implementation of standard procedures (Figs 2 and 3).

After the surgery, the anesthesia workstation was disinfected for two hours with an anesthesia circuit sterilizer (containing 12\% hydrogen peroxide). Chlorinecontaining disinfectant $\left(2,000 \mathrm{mg} \cdot \mathrm{L}^{-1}\right)$ was used to clean the operating room floor and wipe the surface of reusable medical equipment (including the anesthesia workstation and monitors). Reusable medical devices (including surgical instruments) were soaked for $30 \mathrm{~min}$ in 2,000 $\mathrm{mg} \cdot \mathrm{L}^{-1}$ chlorine-containing disinfectant, then sealed and collected into double-layer disposable medical waste bags in the cleaning room and sent to the designated disinfection department by specialized staff. After the operating room

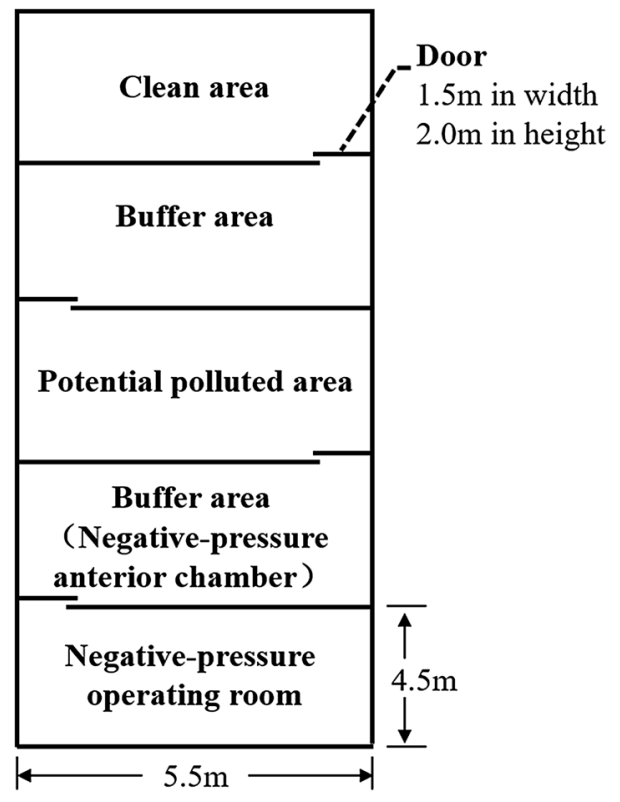

Fig. 1 Overall layout design of surgical workspaces was cleaned, the air purification system was shut down after $30 \mathrm{~min}$ of continuous operation of negative pressure laminar flow. Then, an ultra-low volume of 3\% hydrogen peroxide $\left(20-30 \mathrm{~mL} \cdot \mathrm{m}^{-3}\right)$ was used to closed fumigate the operating room for two hours. Finally, the negative pressure ventilation of the operating room was turned on again.

Anesthesia, surgery, and perioperative management

The anesthesia informed consent was signed by the patient or her relative in the isolation ward or operating room to avoid the possibility of virus spread.

Routine monitoring (continuous non-invasive blood pressure, electrocardiograph, and pulse oximetry) was performed after the patient entered the operating room. Continuous epidural anesthesia or combined spinalepidural anesthesia (CSE) was the first choice to avoid endotracheal intubation (which could induce or exacerbate pulmonary complications in parturients with COVID-19). General anesthesia was an option for cases of maternal or fetal emergencies, or for those patients with contraindications to epidural or CSE techniques, or if intrathecal anesthesia failed.

\section{Conduct of epidural anesthesia}

The L3-4 or L2-3 interspace was selected as the epidural puncture site. $2 \%$ lidocaine was used as both the test dose and loading dose; $0.75 \%$ ropivacaine was used for maintenance of epidural anesthesia. A sensory and motor block plane from T6-T8 segments to S4-5 was maintained during Cesarean delivery.

\section{Conduct of general anesthesia}

For cases needing general anesthetic for Cesarean delivery, preoxygenation was rapidly accomplished with four maximal capacity breaths with $100 \%$ oxygen. Rapid inhalation induction of general anesthesia consisted of $8 \%$ sevoflurane in $100 \%$ oxygen while cricoid pressure was continuously applied, and following two to three minutes of gentle positive pressure ventilation. This was followed by intravenous injections of $2 \%$ lidocaine $\left(1-1.5 \mathrm{mg} \cdot \mathrm{kg}^{-1}\right)$, remifentanil (1-2 $\left.\mathrm{mg} \cdot \mathrm{kg}^{-1}\right)$ and succinylcholine choline (1-2 $\left.\mathrm{mg} \cdot \mathrm{kg}^{-1}\right)$ to ensure optimal intubating conditions. Sevoflurane was used to maintain anesthesia before delivery, with sufentanil $\left(0.25-0.35 \mu \mathrm{g} \cdot \mathrm{kg}^{-1}\right)$ and an infusion of propofol $\left(50-100 \mu \mathrm{g} \cdot \mathrm{kg}^{1} \cdot \mathrm{min}^{-1}\right)$ used to maintain anesthesia after delivery. 


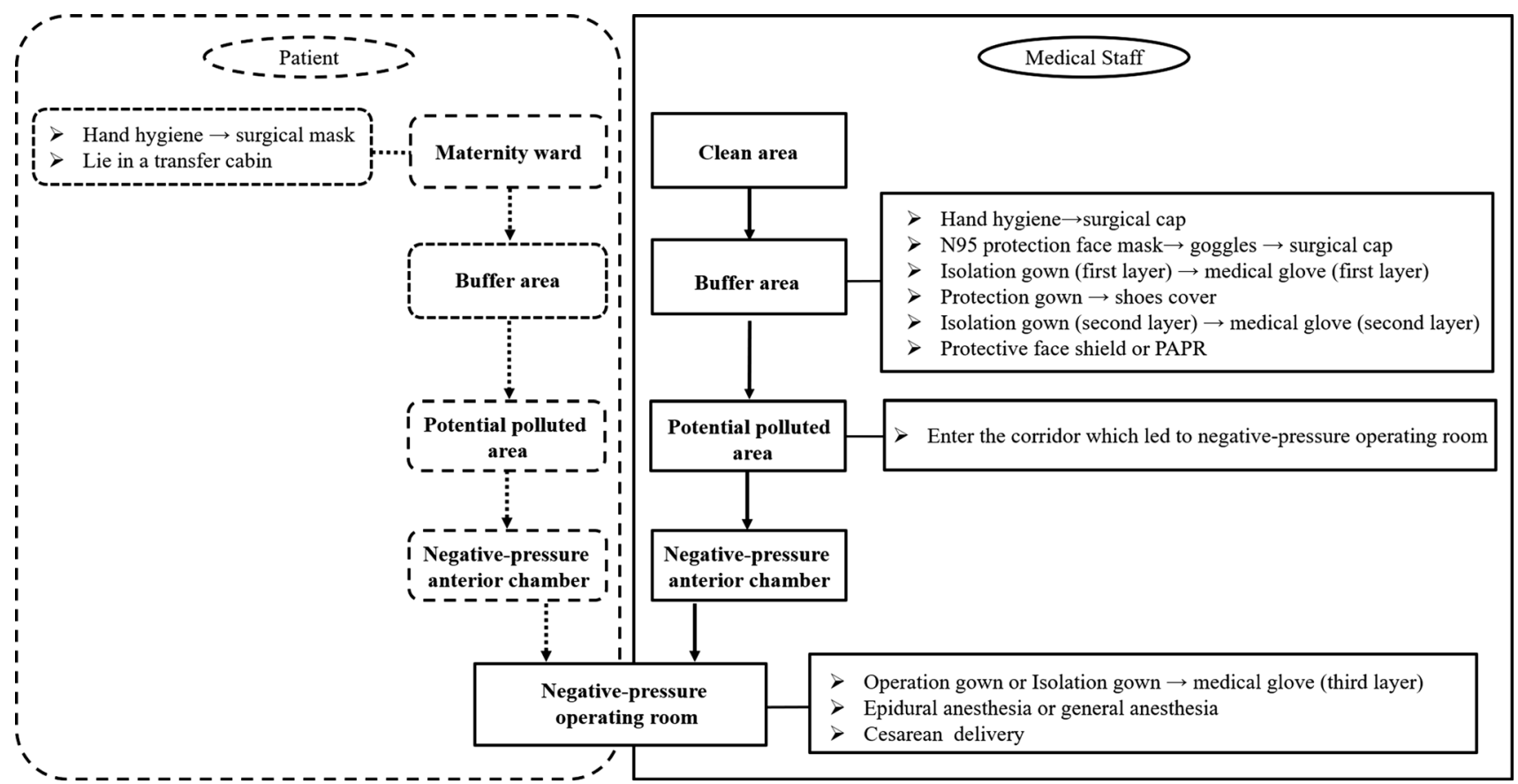

Fig. 2 Standard operating procedures for dressing biosafety level 3 protective medical equipment

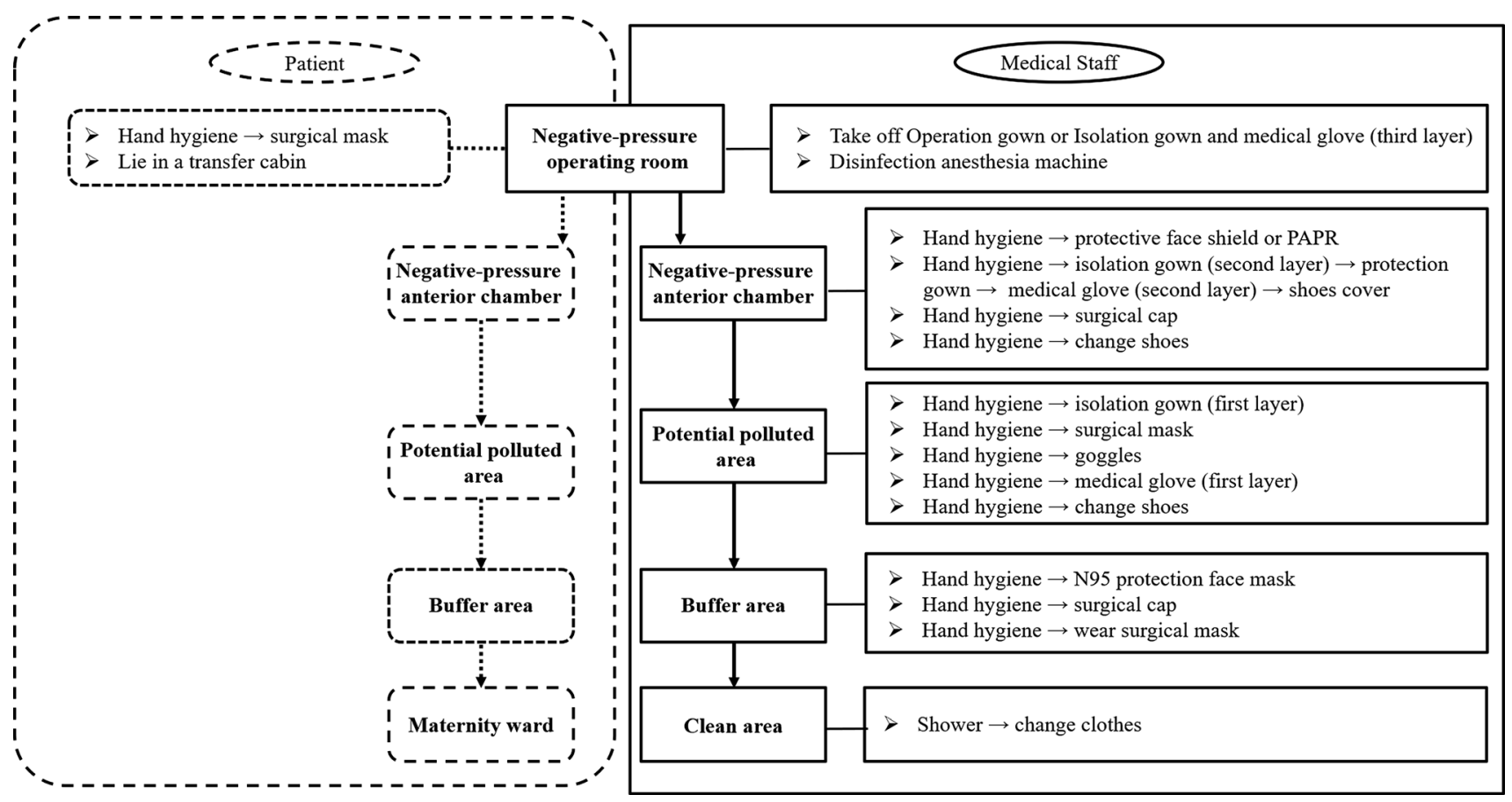

Fig. 3 Standard operating procedures for undressing biosafety level 3 grade protective wear

Outcomes of both mothers and newborns

All parturients presenting to hospital were queried as to whether they had a history of exposure to, or were diagnosed with COVID-19 within the prior 14 days. The method of delivery, American Society of Anesthesiologists
(ASA) physical status score, arterial blood gases, operation time, estimated blood loss, postoperative visual analogue score (VAS) for pain, any need for analgesia within the first 48 postpartum hours, as well as maternal complications and outcomes were also recorded. 
After delivery, the newborns' oral cavity, nose, and face were wiped and cleaned immediately with a sterile towel. The newborns were then transferred to a radiant warmer bed in a cordoned-off area in the operating room. The Apgar score was assessed at one, five, and ten minutes after delivery. After ligation of the umbilical cord, newborns were sent to the neonatal intensive care unit (NICU) by specialized nurses and no further contact with infected mothers was allowed. A blood gas from the newborn was measured in NICU. A SARS-CoV-2 RT-PCR viral test (nasal swab) for neonates was performed twice, first on the day after delivery and then again on the day before discharged. Neonatal mortality, severe asphyxia, NICU length of stay, and other clinical outcomes were also recorded.

Postoperative evaluation of medical staff

All medical staff who were involved in the Cesarean delivery were required to have a SARS-CoV-2 virus detection test (RT-PCR of nasal swabs) and CT scans once every two weeks.

\section{Data presentation}

Data were presented as mean (standard deviation), median [interquartile range], or $n(\%)$. As the overall number of cases was relatively small, no inferential statistical analysis was undertaken.

\section{Results}

Demographic data

Seventeen parturients with COVID-19 were included in this study. Five parturients (29\%) had anemia, one (6\%) had gestational hypertension, and two (12\%) had gestational diabetes. All these patients were in a stable condition during pregnancy (Table 1).

\section{Clinical characteristics}

Three parturients (18\%) had been exposed to SARS-CoV2. Two of them were doctors who had been in contact with SARS-CoV-2-positive patients, while one patient's husband worked at the HUANAN Seafood Wholesale Market (once considered to be the source of the COVID-19 outbreak). Four patients (24\%) presented with a mild fever without chills and none had a high fever (temperature $>$ $\left.39^{\circ} \mathrm{C}\right)$. Other symptoms included four patients $(24 \%)$ with cough, one $(6 \%)$ with fatigue, two $(12 \%)$ with "chest distress", one (6\%) with overt dyspnea, and one (6\%) with diarrhea (Table 2).
Five parturients (29\%) with COVID-19 had lymphopenia $\left(<1.0\right.$ cells $\left.\times 10^{9} \cdot \mathrm{L}^{-1}\right)$. Seven patients $(41 \%)$ had elevated concentrations of C-reactive protein $(>$ $10 \mathrm{mg} \cdot \mathrm{L}^{-1}$ ). All patients had a normal level of alanine transaminase, aspartic transaminase, blood urea nitrogen, and creatinine (Table 2). All 17 patients tested positive by RT-PCR for SARS-CoV-2 and presented with multiple patchy ground-glass opacities on chest CT scan. ${ }^{5}$

Anesthesia management and surgery

All the 17 cases underwent Cesarean delivery. Three patients (18\%) received general anesthesia (with endotracheal intubation) and the other 14 patients $(82 \%)$ received continuous epidural anesthesia. An overview of the intraoperative arterial blood gas of the parturients is shown in Table 3. Twelve of the parturients (86\%) undergoing epidural anesthesia experienced a higher rate of intraoperative hypotension (systolic blood pressure < $80 \%$ of baseline) than that in the general anesthesia group. Intraoperative hemodynamic parameters were not improved by left-lateral position, intravenous liquid loading, and/or vasoconstrictor treatment. There were no other apparent clinical differences in other measurements between the general and epidural anesthesia groups. Fourteen patients quickly recovered from COVID-19 and were discharged from hospital after six to 13 days in the hospital. The three patients remaining are still in the hospital as of 1 March 2020 recovering from their Cesarean delivery and COVID-19.

\section{Neonatal outcomes}

All mothers had a singleton pregnancy. No intrapartum death, neonatal death, or serious neonatal asphyxia was observed. Three neonates were born prematurely, but none had a birthweight $<2,500 \mathrm{~g}$ (Table 4). The Apgar scores ranged from 7 to 9 at one minute and 9 to 10 at five minutes (Table 4). All neonates were admitted to the NICU for further care and all SARS-CoV-2 RT-PCR tests were negative. All 17 neonates were eventually discharged from hospital. There were no apparent differences in any parameters of the neonates when comparing the epidural anesthesia group with the general anesthesia group.

\section{Post-evaluation of medical staff infection}

A total of 12 obstetricians, ten anesthesiologists, and 26 nurses were involved in the Cesarean deliveries. All medical staff used BSL-3 protective equipment during the operation. Thus far, none have been infected with the SARS-CoV-2 according to the RT-PCR testing and CT scan findings. 
Table 1 Demographic data $(n=17)$

\begin{tabular}{lll}
\hline & Epidural anesthesia $(n=14)$ & General anesthesia $(n=3)$ \\
\hline Age, yr & $29.5(3.1)$ & $28.7(1.6)$ \\
Height, cm & $160.3(2.4)$ & $161.0(1.7)$ \\
Weight, kg & $65.6(3.4)$ & $65.7(2.89)$ \\
Gestational age & & \\
$<37$ weeks, $n(\%)$ & $3(21)$ & 0 \\
$\geq 37$ weeks, $n(\%)$ & $11(79)$ & $3(100)$ \\
Coexisting disorders & $8(57)$ & 0 \\
Anemia, $n(\%)$ & $5(36)$ & 0 \\
Hypertension, $n(\%)$ & $1(7)$ & 0 \\
Diabetes, $n(\%)$ & $2(14)$ & 0 \\
\hline
\end{tabular}

Data are presented as mean (standard deviation) or $n(\%)$, as indicated

Anemia is defined as hemoglobin level of $<11 \mathrm{~g} \cdot \mathrm{L}^{-1}$; Hypertension is defined as a systolic blood pressure $>140 \mathrm{mmHg}$ and/or a diastolic blood pressure $>90 \mathrm{mmHg}$ (average of at least two measurements taken at least $15 \mathrm{~min}$ apart); Diabetes is defined as fasting blood glucose concentration $>7.0 \mathrm{mmol} \cdot \mathrm{L}^{-1}$ or two-hour blood glucose concentration $>11.1 \mathrm{mmol} \cdot \mathrm{L}^{-1}$

Table 2 Clinical characteristics $(n=17)$

\begin{tabular}{|c|c|c|}
\hline & Epidural anesthesia $(n=14)$ & General anesthesia $(n=3)$ \\
\hline Epidemiological exposure to SARS-CoV-2, $n(\%)$ & $3(21)$ & 0 \\
\hline \multicolumn{3}{|l|}{ Signs and symptoms } \\
\hline Fever, $n(\%)$ & $4(29)$ & 0 \\
\hline Cough, $n(\%)$ & $4(29)$ & 0 \\
\hline Fatigue, $n(\%)$ & $1(7)$ & 0 \\
\hline Chest distress, $n(\%)$ & $2(14)$ & 0 \\
\hline Dyspnea, $n(\%)$ & $1(7)$ & 0 \\
\hline Diarrhea, $n(\%)$ & $1(7)$ & 0 \\
\hline \multicolumn{3}{|l|}{ Laboratory characteristics } \\
\hline Leukocyte count, $\times 10^{9} \cdot \mathrm{L}^{-1}$ & $9.1(3.6)$ & $12.7(6.2)$ \\
\hline Leukocytosis $\left(>10 \times 10^{9} \cdot \mathrm{L}^{-1}\right), n(\%)$ & $4(28.6)$ & $2(66.7)$ \\
\hline Lymphocyte count, $\left.\times 10^{9} \cdot \mathrm{L}^{-1}\right)$ & $1.1(0.3)$ & $1.34(0.3)$ \\
\hline Lymphopenia $\left(<1.0 \times 10^{9} \cdot \mathrm{L}^{-1}\right), n(\%)$ & $5(35.7)$ & 0 \\
\hline CRP concentration, $\mathrm{mg} \cdot \mathrm{L}^{-1}$ & $30.3(8.1)$ & $24.1(21.5)$ \\
\hline Elevated concentrations of CRP $\left(>10 \mathrm{mg} \cdot \mathrm{L}^{-1}\right), n(\%)$ & $6(42.9)$ & $1(33.3)$ \\
\hline ALT concentration, $\mathrm{U} \cdot \mathrm{L}^{-1}$ & $18.9(5.4)$ & $22.3(12.1)$ \\
\hline AST concentration, $\mathrm{U} \cdot \mathrm{L}^{-1}$ & $21.4(8.9)$ & $25.3(14.6)$ \\
\hline BUN concentration, $\mathrm{mM}$ & $3.0(0.7)$ & $4.0(0.8)$ \\
\hline SCr concentration, $\mu \mathrm{M}$ & $41.7(7.4)$ & $51(7.6)$ \\
\hline CT evidence of pneumonia, $n(\%)$ & $14(100)$ & $3(100)$ \\
\hline
\end{tabular}

Data are presented as mean (standard deviation) or $n(\%)$, as indicated

$\mathrm{ALT}=$ alanine transaminase; $\mathrm{AST}=$ aspartic transaminase $; \mathrm{BUN}=$ urea nitrogen $\mathrm{CRP}=\mathrm{C}$-reactive protein; $\mathrm{CT}=$ computed tomography; $\mathrm{SARS}$ $\mathrm{CoV}-2=$ severe acute respiratory syndrome coronavirus; $\mathrm{SCr}=$ serum creatinine

\section{Discussion}

Herein we report 17 cases of parturients with COVID-19 having Cesarean delivery. All those patients presented with ground-glass opacities on chest CT scans and laboratoryconfirmed SARS-CoV-2 positivity. Epidural or general anesthesia was safe and effective for surgical patients. Careful patient transfer along with medical staff effective biosafety precautions were likely important to protect medical staff from SARS-CoV-2 infection.

Clinical features of SARS-CoV-2 infection share some similarity with previous reports of SARS-CoV and Middle 
Table 3 Anesthesia management and surgery $(n=17)$

\begin{tabular}{|c|c|c|}
\hline & Epidural anesthesia $(n=14)$ & General anesthesia $(n=3)$ \\
\hline \multicolumn{3}{|l|}{ Method of delivery } \\
\hline Elective Cesarean delivery, $n(\%)$ & $14(100)$ & 0 \\
\hline Emergency Cesarean delivery, $n(\%)$ & 0 & $3(100)$ \\
\hline \multicolumn{3}{|l|}{ ASA physical status } \\
\hline I, $n(\%)$ & 0 & 0 \\
\hline II, $n(\%)$ & $13(93)$ & $3(100)$ \\
\hline III, $n(\%)$ & $1(7)$ & 0 \\
\hline $\mathrm{IV}, n(\%)$ & 0 & 0 \\
\hline $\mathrm{V}, n(\%)$ & 0 & 0 \\
\hline \multicolumn{3}{|l|}{ Arterial blood gas analysis } \\
\hline $\mathrm{pH}$ & $7.36(0.03)$ & $7.33(0.02)$ \\
\hline $\mathrm{PaO}_{2}, \mathrm{mmHg}$ & $117(98)$ & $125(92)$ \\
\hline $\mathrm{PaCO}_{2}, \mathrm{mmHg}$ & $32(3)$ & $27(4)$ \\
\hline $\mathrm{HCO}_{3}, \mathrm{mmol} \cdot \mathrm{L}^{-1}$ & $18.9(1.5)$ & $20.4(0.4)$ \\
\hline $\mathrm{BE}, \mathrm{mmol} \cdot \mathrm{L}^{-1}$ & $-5.4(1.7)$ & $-3.5(0.7)$ \\
\hline $\mathrm{K}^{+}, \mathrm{mmol} \cdot \mathrm{L}^{-1}$ & $4.0(0.3)$ & $4.1(0.1)$ \\
\hline $\mathrm{Na}^{+}, \mathrm{mmol} \cdot \mathrm{L}^{-1}$ & $135(4)$ & $136.0(0)$ \\
\hline Glu, $\mathrm{mmol} \cdot \mathrm{L}^{-1}$ & $7.1(1.8)$ & $6.3(0.2)$ \\
\hline $\mathrm{Hb}, \mathrm{g} \cdot \mathrm{L}^{-1}$ & $116.1(13.1)$ & $118.3(0.6)$ \\
\hline Duration of operation, min & 68 (13) & $80(20)$ \\
\hline Blood loss, $\mathrm{mL}$ & $307(92)$ & $300(100)$ \\
\hline Postoperative VAS & $2[1-4]$ & $3[2-4]$ \\
\hline \multicolumn{3}{|l|}{ Occurrence of complications } \\
\hline Hypotension, $n(\%)$ & $12(86)$ & 0 \\
\hline Post-Cesarean delivery length of stay, day & $10(4)$ & $8(3)$ \\
\hline \multicolumn{3}{|l|}{ Clinical outcomes } \\
\hline Discharge from hospital, $n(\%)$ & $12(86)$ & $2(67)$ \\
\hline Recovered, $n(\%)$ & $12(86)$ & $2(67)$ \\
\hline
\end{tabular}

Data are presented as mean (standard deviation), median [interquartile range], or $n(\%)$ as indicated. Hypotension is defined as systolic blood pressure $<80 \%$ of baseline

ASA = American Society of Anesthesiologists; $\mathrm{BE}=$ base excess; Glu = glucose; $\mathrm{Hb}=$ hemoglobin; VAS = visual analogue scale/score

East respiratory syndrome virus (MERS-CoV) infections. ${ }^{6,7}$ Most of those patients present with fever, dry cough, dyspnea, along with bilateral ground-glass opacities on chest CT scan, and patients with severe illness rapidly developed acute respiratory distress syndrome and required intensive care unit admission. Nevertheless, COVID-19 patients rarely developed gastrointestinal signs and symptoms, whereas about $20-25 \%$ of patients with MERS-CoV or SARS-CoV infection had diarrhea. In our experience, the 17 parturients with COVID-19 showed non-classical clinical characteristics. There were only two cases with chest distress and only one case with dyspnea. Nevertheless, none were hypoxemic or required supplemental oxygen prior to the operation. Nine of the parturients did not have typical symptoms such as fever and cough; instead they only showed abnormalities on the chest CT scan. These nine patients had only mild symptoms or were asymptomatic.

In this report, the proportion of maternal critical illness appeared much lower than the average proportion of SARS-CoV-2 infection in Wuhan. ${ }^{8}$ One of the reasons may be that patients had a reduced range of activity and had less chance of exposure to SARS-CoV-2 during late pregnancy. Two recent studies have also shown that SARS-CoV-2 virus has not been detected in amniotic fluid, cord blood, or breast milk of pregnant women infected with SARS-CoV2. 9 This may explain why all the neonates in this study were free from infection. Our result is also consistent with the observation that the incidence of disease and disease severity were lower in neonates than in adults during the SARS epidemic, which may be related to the difficulty of vertical transmission of coronavirus, ${ }^{10}$ proper handling at 
Table 4 Neonatal outcomes $(n=17)$

\begin{tabular}{|c|c|c|}
\hline & Epidural anesthesia $(n=14)$ & General anesthesia $(n=3)$ \\
\hline Neonatal death, $n(\%)$ & 0 & 0 \\
\hline Severe neonatal asphyxia, $n(\%)$ & 0 & 0 \\
\hline \multicolumn{3}{|l|}{ Apgar score } \\
\hline $1 \mathrm{~min}$ & $9[8-9]$ & 9 [7-9] \\
\hline $5 \min$ & $10[9-10]$ & $10[9-10]$ \\
\hline $10 \mathrm{~min}$ & $10[9-10]$ & $10[9-10]$ \\
\hline Birth weight, $g$ & $3,280(330)$ & $2,780(180)$ \\
\hline Low-birth weight $(<2,500 \mathrm{~g}), n(\%)$ & 0 & 0 \\
\hline Neonatal acidosis (umbilical artery $\mathrm{pH}<7.2$ ), $n(\%)$ & 0 & 0 \\
\hline \multicolumn{3}{|l|}{ Arterial blood gas } \\
\hline $\mathrm{pH}$ & $7.36(0.06)$ & $7.35(0.05)$ \\
\hline $\mathrm{PaO}_{2}, \mathrm{mmHg}$ & $69(16)$ & $77(3)$ \\
\hline $\mathrm{PaCO}_{2}, \mathrm{mmHg}$ & $35(7)$ & $40(4)$ \\
\hline $\mathrm{HCO}_{3}, \mathrm{mmol} \cdot \mathrm{L}^{-1}$ & $19.9(2.2)$ & $21.2(0.5)$ \\
\hline $\mathrm{Hb}, \mathrm{g} \cdot \mathrm{L}^{-1}$ & $182.1(8.2)$ & $171.7(11.6)$ \\
\hline SARS-CoV-2 positive, $n(\%)$ & 0 & 0 \\
\hline Duration of neonate ICU, hr & $13(6)$ & $16(2)$ \\
\hline \multicolumn{3}{|l|}{ Clinical outcomes } \\
\hline Discharge from hospital, $n(\%)$ & $14(100)$ & $3(100)$ \\
\hline In the hospital, $n(\%)$ & 0 & 0 \\
\hline
\end{tabular}

Data are presented as mean (standard deviation), median [interquartile range], or $n(\%)$ as indicated

$\mathrm{BE}=$ base excess $; \mathrm{Glu}=$ glucose $; \mathrm{Hb}=$ hemoglobin; $\mathrm{ICU}=$ intensive care unit; SARS-CoV-2 = severe acute respiratory syndrome coronavirus

birth, and timely isolation of the neonate after birth. A recent study showed that in addition to the lung, SARSCoV-2 targets other organs such as kidney and testicles. ${ }^{11}$ It cannot be ruled out that SARS-CoV-2 may have an impact on the placenta. Thus, to ensure the safety of the parturients and newborns, we chose to perform elective Cesarean delivery.

Although we recommend elective Cesarean delivery, there is a paucity of data to drive these recommendations. The final choice for the delivery method needs to consider the parturient's condition, the wishes of the parturient, and the advice of the obstetrician. The potential for transfer of the virus to the fetus during vaginal delivery is not known. If there is intrauterine fetal distress caused by hypoxia and other reasons, emergency Cesarean delivery should be performed immediately. In this study, three parturients underwent emergency Cesarean delivery because of fetal stress.

Although no adverse maternal or neonatal outcomes were observed, COVID-19 can cause quick deterioration of lung function, so the ideal timing of Cesarean delivery is still crucial to ensuring maternal and fetal safety. Although both neuraxial and general anesthesia have been safely reported in pregnancy, ${ }^{12}$ because the lung is the main target organ of the virus, the choice of anesthetic regimens for
Cesarean delivery is critical for pregnant women with COVID-19. Therefore, we recommend that neuraxial anesthesia wherever possible, based on it reducing the possibility of exacerbating pulmonary complications due to intubation. In our study, 14 of 17 pregnant women underwent epidural anesthesia, the onset time of sensory and motor block, the degree of motor block, the height of sensation, and the quality of anesthesia appeared to be the same as those of non-infected pregnant women. Nevertheless, it was noted that $86 \%$ of parturients undergoing epidural anesthesia experienced intraoperative hypotension. Importantly, because of the short duration and the hemodynamic changes, no adverse end-organ damage was apparent. As for why there appeared to be significant hypotension, a recent study suggested that SARS-CoV-2 can bind with the angiotensin-converting enzyme II (ACE2) receptor. ${ }^{13}$ The key of SARS-CoV-2 infection is its $\mathrm{S}$ protein binding with ACE2 receptor. ${ }^{14}$ These studies imply that the circulatory system is highly susceptible to SARS-CoV-2 infection. General anesthesia was used in three of our SARS-CoV-2-infected parturients. General anesthesia did not have any adverse effects on the neonatal outcomes and mothers' recovery from COVID-19.

SARS-CoV-2 is easily spread from person to person via various routes. Respiratory droplets and close contact 
transmission are the main routes of transmission. There is a possibility of aerosol transmission in a relatively closed environment when exposed to high concentrations of aerosol for a long time. To solve the safety issues such as environmental pollution and infection of medical staff with COVID-19, all medical staff involved in the operation need to be identified. They should be trained in proper infection control management procedures and have a thorough understanding of nosocomial infection control and risk factors for COVID-19. In this series of patients, no medical staff involved in the operation were infected with COVID-19. Several factors may have influenced this positive result. First, a specific patient negative pressure transfer vehicle and a dedicated negative pressure operating room were used to prevent the spread of the virus, and sterilization was performed after surgery. Second, patients and medical staff followed the established biosafety procedures when entering and leaving the operating room. Dedicated personnel wore protective equipment and infection control in the negative pressure anterior chamber and buffer room to improve efficiency. Third, parturients wore a surgical mask in case they coughed during tracheal intubation, and suctioning reduced the spread of respiratory droplets and aerosols.

In summary, our experience is that both epidural and general anesthesia are safe and effective for pregnant women and newborns. Nevertheless, the incidence of hypotension appeared to be significantly higher than normal during epidural anesthesia. A negative pressure operating room, proper patient transfer, medical staff access procedures, and effective biosafety precautions were also important to protect the medical staff from SARS-CoV-2 infection. This experience may be helpful in planning for further obstetric anesthetic management of COVID-19 patients, particularly if the infection progresses to pandemic status.

Acknowledgements The authors thank Prof. Daqing Ma, Imperial College London for his critical comment during manuscript preparation.

Conflicts of interest None.

Funding statement None.

Editorial responsibility This submission was handled by Dr. Hilary P. Grocott, Editor-in-Chief, Canadian Journal of Anesthesia.

\section{References}

1. Yang $X, Y u Y, X u J$, et al. Clinical course and outcomes of critically ill patients with SARS-CoV-2 pneumonia in Wuhan, China: a single-centered, retrospective, observational study. Lancet Respir Med 2020. DOI: https://doi.org/10.1016/S22132600(20)30079-5.

2. $X u X W, W u X X$, Jiang $X G$, et al. Clinical findings in a group of patients infected with the 2019 novel coronavirus (SARS-Cov-2) outside of Wuhan, China: retrospective case series. BMJ 2019. DOI: https://doi.org/10.1136/bmj.m606.

3. Huang C, Wang $Y, L i X$, et al. Clinical features of patients infected with 2019 novel coronavirus in Wuhan, China. Lancet 2020; 395: 497-506.

4. Wax RS, Christian MD. Practical recommendations for critical care and anesthesiology teams caring for novel coronavirus (2019-nCoV) patients. Can J Anesth 2020. DOI: https://doi.org/ 10.1007/s12630-020-01591-x.

5. Chen $R$, Chen J, Meng $Q$. Chest computed tomography images of early coronavirus disease (COVID-19). Can J Anesth 2020. DOI: https://doi.org/10.1007/s12630-020-01625-4.

6. Lee $N$, Hui $D, W u A$, et al. A major outbreak of severe acute respiratory syndrome in Hong Kong. N Engl J Med 2003; 348: 1986-94.

7. Assiri A, Al-Tawfiq JA, Al-Rabeeah AA, et al. Epidemiological, demographic, and clinical characteristics of 47 cases of Middle East respiratory syndrome coronavirus disease from Saudi Arabia: a descriptive study. Lancet Infect Dis 2013; 13: 752-61.

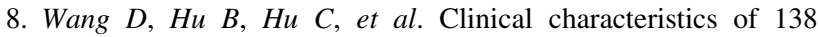
hospitalized patients with 2019 novel coronavirus-infected pneumonia in Wuhan, China. JAMA 2019. DOI: https://doi.org/ 10.1001/jama.2020.1585.

9. Chen H, Guo J, Wang C, et al. Clinical characteristics and intrauterine vertical transmission potential of COVID-19 infection in nine pregnant women: a retrospective review of medical records. Lancet 2020. DOI: https://doi.org/10.1016/ S0140-6736(20)30360-3.

10. Gagneur A, Dirson E, Audebert $S$, et al. Vertical transmission of human coronavirus. Prospective pilot study (French). Pathol Biol (Paris) 2007; 55: 525-30.

11. Fan C, Li K, Ding $Y$, Lu WL, Wang J. ACE2 expression in kidney and testis may cause kidney and testis damage after 2019-nCoV infection. Urology 2020. DOI: https://doi.org/10.1101/2020.02. 12.20022418.

12. Birnbach DJ, Bateman BT. Obstetric anesthesia: leading the way in patient safety. Obstet Gynecol Clin N Am 2019; 46: 329-37.

13. Zhou P, Yang XL, Wang XG, et al. A pneumonia outbreak associated with a new coronavirus of probable bat origin. Nature 2020. DOI: https://doi.org/10.1038/s41586-020-2012-7.

14. $\mathrm{Lu} R$, Zhao $\mathrm{X}, \mathrm{Li} \mathrm{J}$, et al. Genomic characterisation and epidemiology of 2019 novel coronavirus: implications for virus origins and receptor binding. Lancet 2019. DOI: https://doi.org/ 10.1016/S0140-6736(20)30251-8.

Publisher's Note Springer Nature remains neutral with regard to jurisdictional claims in published maps and institutional affiliations. 